Zusammenfassend kann gesagt werden, daß zur Bestimmung der Absorptionsrate eines Stoffes lediglich der Vergleich der Flächen unter den Kurven nach intravenöser und nach nicht-intravenöser Gabe derselben Dosis bei derselben Versuchsperson nötig ist.
Die Relation der Flächen entspricht der Absorptionsrate. Damit ist das Verfahren zur pharmakokinetischen Prüfung der Vollständigkeit der Absorption geeignet und experimentell bestätigt.

\title{
Literatur
}

1. Dosr, F. H., Klin. Wschr. II, 655 (1958). - 2. Dost, F. H., Antibiotica et chemotherapia, im Druck. - 3. Dosr, F. H., Dtsch. med. Wschr. II, 1833 (1962). - 4. Moeller, J. und L. Aвt, Klin. Wschr. I, 340 (1952). - 5. GladtKe, E. und E. Mohos, Veröffentlichung in Vorbereitung. - 6. SCHMIDT, K., S. TRIPOD und F. Gross, Klin. Wschr. 38, 862 (1960). - 7. Bratron, A. C. und E. K. Marshatr, J. Biol. Chem., Baltimore, 128, 537 (1939). 8. Matrenhermer, H., Mikromethoden für das klinisch-chemische und biochemische Laboratorium, Walter de Gruyter \& Co., Berlin (1961), S. 9-12.
Professor Dr. F. H. Dost

Direktor der Universitätskinderklinik 63 Gießen, Klinikstr. 28

\section{Untersuchungen über das Verhalten der Plasmalipoide bei idiopathischer Hypercholesterinämie, unter besonderer Berücksichtigung der Cholesterinester ${ }^{1)}$}

\author{
Von \\ NePOMUK ZÖLLNER \\ Aus der Medizinischen Poliklinik der Universität München (Diriktor: Prof Dr. W. Seitz). \\ (Der Schriftleitung zugegangen am 1. September 1962)
}

\begin{abstract}
Es wird ein System von Lipoidanalysen beschrieben, das es gestattet, aus einem Lipoidextrakt von $1 \mathrm{ml}$ Serum alle wesentlichen Lipoidgruppen mit Ausnahme der freien Fettsäuren im Doppel zu bestimmen. Die Analyse der Cholesterinester bei Fällen von idiopathischer Hypercholesterinämie ergibt eine normale Verteilung der Cholesterinesterfettsäuren. Dies wird als Beweis dafür angesprochen, daß eine Störung des Cholesterinesterstoffwechsels bei der idiopathischen Hypercholesterinämie nicht vorliegt. Eine vergteichende Untersuchung über die quantitative Bestimmung der Cholesterinester mittels Dünnschicht- oder Gaschromatographie ergibt gute Übereinstimmung beider Methoden.
\end{abstract}

A method is described by which all important groups of lipids except free fatty acids can be determined in duplicate in the lipid extract from $1 \mathrm{ml}$ serum. The analysis of cholesterol esters in idiopathic hypercholesterolaemia gives a normal distribution of cholesterol fatty acids. This is evidence that cholesterol ester metabolism is not disturbed in idiopathic hypercholesterolaemia. Comparison of quantitative cholesterol ester determination by thin layer and gas chromatography shows good agreement.

Die idiopathische familiäre Hypercholesterinämie ist eine angeborene Stoffwechselstörung auf der Grundlage eines genetischen Defektes. Die Grundzüge der Klinik dieser nicht allzu seltenen Krankheit sind durch die klassischen Beschreibungen von Thannhauser und Magendantz (1) sowie Thannhauser (2) dargestellt. Auch die Genetik ist weitgehend bekannt (FrEDRICKSON (3)), wenngleich die erhobenen Befunde noch nicht einheitlich gedeutet werden. Die Abgrenzung der Krankheit gegen die idiopathische Hyperlipämie macht nur gelegentlich noch Schwierigkeiten.

1) Dem Andenken meines verehrten Lehrers Sregrimind. ThanNHAUSER, gestorben am 18. Dez. 1962, gewidmet.
Über die Natur des der idiopathischen familiären Hypercholesterinämie zugrundeliegenden Stoffwechseldefektes ist man noch völlig im Dunkeln. Dies ist verständlich, weil bislang nur bekannt ist, $\mathrm{da}$ B Cholesterin und die Summe seiner Ester in normalen Proportionen vermehrt sind (2). Daneben beobachtet man eine Vermehrung der Phosphatide $(3,4,5)$. und - häufig - der Carotinoide (6). Alle Angaben überLipoidvermehrungen bei der Krankheit beziehen sich also auf Substanzgruppen. Hinweise auf die Lage eines Stoffwechselblocks sind aber erfahrungsgemä $B$ in erster Linie aus der Anhäufung einer individuellen Substanz zu erwarten. Daraus ergibt sich die Forderung, die Analytik bis zur Bestimmung einzelner Lipoide voranzutreiben. Ent- 
sprechende Untersuchungen auf dem Gebiet der Cholesterinester sind daher Gegenstand der vorliegenden Untersuchung.

\section{Methodik}

\section{A. Allgemeine Methoden zur Analyse der Plasmalipoide' ${ }^{1}$ )}

$V$ enenblut wird morgens vom nüchternen Patienten gewonnen. Durch Rückfrage wird sichergestellt, daß die Mahlzeit des Vorabends nicht fettreich war. Sobald wie möglich, jedenfalls innerhalb weniger Stunden wird abzentrifugiert und Serum vom'Blutkuchen abgetrennt. Hämolytisches Serum wird verworfen. Für säulenund gaschromatographische Untersuchungen wird Heparin- oder Oxalatplasma durch Zentrifugieren bei $3^{\circ}-5^{\circ}$ sofort nach Blutabnahme gewonnen. Auf die Ergebnisse bezüglich Cholesterin und Cholesterinester hat dieses Vorgehen keinen exkennbaren Einfluß.

Die Messung der lipämischen Trübung erfolgt entweder mit Rotfilter 691 im Eppendorf-Photometer oder bei $691 \mathrm{~m} \mu$ in einem Spcktrophotometer $\left(\mathrm{d}=1 \mathrm{~cm}\right.$, Vergleichslösung $\left.\mathrm{H}_{2} \mathrm{O}\right)$. Die Ergebnisse mit Filter- und Spektrophotometer sind nicht vergleichbar aber Extinktionswerte über $\varepsilon=0,1$ weisen jedenfalls auf erhöhte Neutralfettwerte hin, meist verursacht durch eine fettreiche Mahlzeit am Vorabend. Eine Wiederholung aller Lipoidbestimmungen nach einem Tag zuverlässig fettarmer Ernährung ist dann angezeigt.

Die Herstelling eines Lipoidextraktes aus dem Serum erfolgt durch tropfenweise Zugabe von $1 \mathrm{ml}$ Serum (oder Plasma) zu $16 \mathrm{ml}$ Chloroform-Methanol 1:1 $(\nabla: \nabla)$. Es wird im Wasserbad kurz zum Sieden gebracht, nach Abküblen mit Chloroform auf $25 \mathrm{ml}$ aufgefüllt und durch ein schnellaufendes Filter (Abdeckung mit Uhrglas) filtriert. Diese Art der Extraktion mit ChloroformMethanol (Endverhältnis 2:1 ( $v: v)$ ) erfaßt die Plamalipoide quantitativ. Sie ist unter Beibehaltung der Mengenverhältnisse auch für größere Serumproben geeignet. Ob die kurze Erhitzung und die Lösungsmittelmenge auch für Organhomogenate ausreicht, ist jeweils zu prüfen.

Die Reinigung des Lipcidextraktes erfolgt, in Anlehnung an eine Methode von ForCH, mitgeteilt von SpERRY (7), durch Ausschütteln von $20 \mathrm{ml}$ filtriertem Lipoidextrakt mit $4 \mathrm{ml} 0,02 \%$ väßriger $\mathrm{CaCl}_{2}$-Lösung in einem graduierten Schüttelzylinder von $25 \mathrm{ml}$. Durch Zugabe des Wassers entsteht eine obere Wasser-MethanolPhase, die alle nichtlipoiden Verunreinigungen aufnimmt (Kohlenhydrate, Aminosäuren, Elektrolyte). Durch den Gehalt an $\mathrm{CaCl}_{-2}$ werden Phosphatidverluste in die obere Phase vermieden. Das Volumen der unteren, lipoidhaltigen Phase (kurz ,untere Phase ") beträgt etwa $14 \mathrm{ml}$; es wird auf $0,1 \mathrm{ml}$ genau abgelesen und notiert. Die obere. Phase wird quantitativ abgesaugt, gegebenenfalls unter Verlust von etwas unterer Phase. Von der unteren Phase werden aliquote Teile genommen, eingeengt und in die weiteren Analysen eingesetzt.

Bei allen Arbeiten mit Lipoidlösungen ist die Flüchtigkeit dẹ Lösungsmittel in Rechnung zu stellen. Prinzipiell sind leichtflïchtige Lösungsmittel für Mikromethoden ungeeignet. Daher haben wir aufgehört, Äther zu verwenden. Es ist darauf zu achten, daß Gefäße vor der Entnahme aliquoter Teile weitgehend gefiillt und gut verschlossen sind (außer zum Erhitzen, das wir aber so weit wie möglich vermeiden). Bei längerer Aufbewahrung von Lipoidlösungen ist immer mit Volumenverlusten $z u$ rechnen; ist eine längere Aufbewahrung nicht zu umgehen, so ist bis zu dem utsprünglichen Volumen aufzufüllen. Wegen der Neigung von Lipoidlösungsmitteln 7u „,kriechen“ isț es zweckmäßig, immer verhältnismäßig große Volumina zu pipettieren und erst anschließend einzuengen; im allgemeinen arbeiten wir mit Volumen von wenigstens $1 \mathrm{ml}$, gegebenenfalls nach Vorverdünnung. Bei Verwendung von Mikropipetten können Meßungenauigkeiten durch Pipettierverlust sehr beträchtlich werden.

1) Die ausführliche Beschreibung der z. T. bereits an anderen Orten publizierten Methodik erfolgt auf Wunsch der Schriftleitung.
Das Einengen der Lipoidextrakte erfolgt auf dem Wasser- oder Sandbad bei Temperaturen knapp über dem Siedepunkt der verwendeten Lösungsmittel. Kochende Wasserbäder sind, auch wegen der Bildung von Kondenswasser in den Probengläsern, zu vermciden. Die-letzten Lösungsmittelreste werden mit einem Stickstoffstrom verjagt. Große Lösungmittelmengen verdampfen wir im Vakuum. Für viele Routineuntersuchungen (Gesamtcholesterin, Lipoidphosphor) ist die Anwendung von Stickstoff nicht nötig, wenn darauf geachtet wird, daß der Trockenrückstand nicht weiter erhitzt wird. Es ist darauf $\mathrm{zu}$ achten, daß die eingetrockneten $\mathrm{Li}$ poide umgehend im nächsten Lösungsmittel aufgenommen werden.

Die im folgenden empfohlenen Methoden wurden im Hinblick auf größtmögliche Spezifität bei Einsatz kleiner Substanzmengen ausgewählt. Alle zusammen können als Doppelbestimmungen aus der unteren Phase eines Lipoidextraktes von $1 \mathrm{ml}$ Serum durchgeführt werden.

Die Bestimmung des Cholesterins erfolgt nach $Z_{A K}$ u. M. $(8,9)$ mit Hilfe derEisenchloridreaktion (LIFsCHürzsche Reaktion). Der Vorteil dieser Reaktion gegenüber der LIEBERMANN-BurChardschen Reaktion besteht in einer größeren Empfindlichkeit und einer größeren Stabilität der gebildeten Farbe. Wie wir uns durch Kontrolluntersuchungen vergewissern konnten, ist die Reaktion bei Anwendung auf einen in der beschriebenen Weise gereinigten Serumlipoidextrakt für Cholesterin selektiv. Zur Bestimmung des Gesamtcholesterins erübrigt sich damit die Digitoninfällung. Für die Eisenchloridmethode sind mehrere Modifikationen angegeben worden. Am einfachsten ist es, den zu untersuchenden trockenen Lipoidrückstand in $3 \mathrm{ml}$ Eisessig zu lösen, mit $2 \mathrm{ml}$ Reagenz (zu 7,5 ml konzentrierter Schwefelsäure gibt man $0,5 \mathrm{ml} 10 \%$ wäßrige $\mathrm{FeCl}_{3}$-Lösung und füllt nach Mischen auf $50 \mathrm{ml} \mathrm{mit} \mathrm{konzentrierter} \mathrm{Schwefel-}$ säure auf) zu unterschichten, sehr rasch zu mischen und nach $1 / 2$ bis 1 Std. bei $560 \mathrm{~m} \mu$ (oder im EppendorfPhotometer, Filter 546) zu photometrieren. Ein Standardwert mit $50 \mu \mathrm{g}$ Cholesterin in $3 \mathrm{ml}$ Eisessig wird parallel bestimmt, und gibt, je nach Photometer, in: der $1 \mathrm{~cm}$ Küvette Extinktionswerte zwischen 0,240 und 0,290. Dementsprechend setzt man für Gesamtcholesterinbestimmungen $1 \mathrm{ml}$ untere Phase, für Bestimmungen des freien Cholesterins $2 \mathrm{ml}$ untere Phase ein. Bei Seren mit hohen Cholesterinwerten ist für die Gesamtcholesterinbestimmung eine Vorverdünnung nötig. Die Bestimmung des freien Cholesterins erfolgt nach Digitoninfällung unter präziser Einhaltung der Originalangaben von $Z_{A K}$ und Mitarbeitern.

Auf eine quantitative Entfernung des Digitoninüberschusses ist zu achten, da diese Substanz mit LrFschütz-Reagenz ebenfalls eine Farbe gibt, die bei der angewandten Wellenlänge schwach absorbiert.

Lipoidphosphor wird durch Veraschung des trockenen Lipoidrückstandes und anschließende Entwicklung von Phosphormolybdänblau nach BARTLETT (10) bestimmt. Die Methode ist eine Modifikation der von Frske und SubBaRow angegebenen, erlaubt aber den Nachweis kleinerer Phosphormengen. Vorteilhaft ist die bequeme Veraschung im Brutschrank bei $160^{\circ}$, die abgesehen von einer einmaligen Unterbrechung zur Zugabe von Wasserstoffperoxyd keine Kontrolle erfordert. Ein 
Standardwert von $2 \mu \mathrm{g}$ Orthophosphatphosphor ergibt bei $830 \mathrm{~m} \mu$ Extinktionswerte von $\varepsilon=0,300-0,350$ $(\mathrm{d}=1 \mathrm{~cm})$ nach Abzug des Leerwertes. Da die Methode sehr empfindlich ist, sollte nur mit gesondert, mit.Bichromatschwefelsäure gewaschenen Gläsern gearbeitet werden. Mehrfache Leerwertmessungen dienen der Kontrolle von Gläsern und Reagentien; gute Leerwerte liegen unter $\varepsilon \leqq 0,020$. Für die Gesamtphosphatidbestimmung verdünnt man $2 \mathrm{ml}$ untere Phase mit $2 \mathrm{ml}$ Chloroform und setzt $1 \mathrm{ml}$ des Gemisches ein. Bei sehr hohen Phosphatidspiegeln ist stärker vorzuverdünnen, da die Eichkurve der Methode bei $\varepsilon \geqq 0,700$ abzuflachen beginnt.

Die Bestimmung der veresterten Fettsüuren erfolgt nach Rapport und Alonzo (11). Als Standard wird Triolein Merck verwendet. $d=1 \mathrm{~cm}, \lambda=530 \mathrm{~m} \mu, 450 \mu \mathrm{g}$ Triolein ergeben eine Extinktion von $\varepsilon=0,265$. Dementsprechend werden 1 bis $2 \mathrm{ml}$ untere Phase eingesetzt. Gesamtlipoide werden mit der SulfophosphovanillinReaktion nach Chabrol u. Mitarb. $(12,13)$ in der Modifikation von ZöLLNER und KIRSCH (14) bestimmt. Die Methode, die wahrscheinlich Doppelbindungen in den Lipoiden erfaßt, ergibt bei Einsatz von $50 \mu \mathrm{g}$ Gesamtlipoiden aus Serum bei $530 \mathrm{~m} \mu$ Extinktionswerte $z$ wischen 0,250 und 0,300 in der $1 \mathrm{~cm}$-Küvette. Dementsprechend wird für eineGesamtlipoidbestimmung $1 \mathrm{ml}$ einer 1:10 Verdünnung der unteren Phase eingesetzt. Eine Eichung der Methode ist nicht möglich, da ein heterogenes Gemisch bestimmt wird. Verschiedene Möglichkeiten, die Methode zu standardisieren sind an anderer Stelle (14) besprochen.

Je nachdem, ob als $\mathrm{Maß}$ für die Gesamtlipoide die veresterten Fettsäuren bestimmt werden oder die Sulfophosphovanillin-Reaktion durchgeführt wird, werden für eine Analyse aller Lipoidgruppen $9 \mathrm{bzw} .12 \mathrm{ml}$ untere Phase verbraucht, lediglich die freien Fettsäuren bleiben ununtersucht. Der Rest der unteren Phase kann für Dünnschichtchromatographie verwendet werden. Neutralfette werden aus den Ergebnissen der übrigen Analysen berechnet. Geht man von einer Bestimmung der veresterten Fettsäuren aus, so lautet die Formel (15), unter Berücksichtigung neuerer Angaben von EGGSTEIN (16), (alle Werte in $\mathrm{mg}^{\circ} / \mathrm{o}$ ):

Neutralfett $=1,04 \times$ [veresterte Fettsäuren -

$(0,72 \times$ Estercholesterin $+13,3 \times$ Lipoidphosphor $)]$

Unter Zugrundelegung von Gesamtlipoidwerten lautet die Gleichung (14), (alle Werte in $\mathrm{mg} \%$ ):

Neutralfette $=$ Gesamtlipoide - (Freies Cholesterin + 1,7 $\times$ Estercholesterin + Phosphatide)

Ein Berecbnungsbeispiel sei für den Lipoidphosphor angegeben: Die Doppelanalyse von $0,5 \mathrm{ml}$ unteret Phase $(1 \mathrm{ml}$ einer $1: 2$ Verdünnung) ergab eine Extinktion von $0,274^{\circ}$ und 0,266. Nach Abzug des Leerwertes von 0,017 und Mittelung ergibt sich ein Wert von 0,253, dessen Umrechnung mit einem Eichwert für $2 \mu \mathrm{g}$ von 0,336 einen Phosphorgehalt von 1,5 $\mu \mathrm{g}$ ergibt. Dieser Wert wird mit dem Faktor 2 (Verdünnung), dem Volumen der unteren Phase $(14,1 \mathrm{ml}$ ) und mit 1,25 (Umrechnung auf $1 \mathrm{ml}$ Serum) multipliziert. Daraus ergibt sich, daß $1 \mathrm{ml}$ Serum

$1,5 \times 2 \times 14,1 \times 1,25=53 \mu \mathrm{g}$ Lipoidphosphor enthielten. Das Serum enthielt also $5,3 \mathrm{mg} \%$ Lipoidphosphor. Umrechnung mit dem Faktor 25 ergibt einen Phosphatidgehalt von $132 \mathrm{mg} \%$.

\section{B. Spezielle chromatographische Methoden}

Dünnscbicbtchromatographische Trennungen der Cholesterinester erfolgten wie bereits beschrieben $(17,18)$, ebenso die quantitative Auswertung (18). Die Dünnschichtchromatographie der neutralen Lipoidfraktionen erfolgte mit Fließmittel B nach ZöllNer und Wolfram (19), bestehend aus

Petroläther:Äthylmethylketon:Eisessig 95:4:1 (v:v:v). Die Abtrennung der Cholesterinester von den übrigen neutralen Plasmalipoiden, die Reinheitsprüfung der Fraktion, die Methylveresterung und die anschließenden Gaschromatographien (vor und nach Hydrierung) werden an einem typischen Arbeitsgang erläutert:

Die untere Phase eines Chloroform-Methanol-Extraktes von $3 \mathrm{ml}$ Serum wurde im Vakuum zur Trockene gebracht; Wasserreste wurden nach Zugabe geringer Mengen Äthanols verjagt. Anschließend wurde sofort in $1 \mathrm{ml}$ Petroläther (Kp 40-70') aufgenommen.

Eine Florisil-Säule nach CARROL (20) wurde mit nicht desaktiviertem Florisil bereitet (15 g Florisil, Säulendurchmesser $12 \mathrm{~mm}$ ). Die Petroläther-Lösung der Plasmalipoide'wurde auf die Säule aufgetragen; mit $4 \times 1 \mathrm{ml}-$ Portionen wurde quantitativ nachgespült. Die Chromatographie érfolgte mit $50 \mathrm{ml}$ Petroläther, $200 \mathrm{ml}$ $5 \%$ Äther in Petroläther, $100 \mathrm{ml} \mathrm{25 \%}$ Äther in Petroläther. Die fraktionierte Sammlung des Elluates erfolgte in $5 \mathrm{ml}$ Portionen. Das Chromatogramm (Abb. 1) zeigt eine hinreichende Trennung des Cholesterinestergipfels von allen übrigen Lipoiden. Eine Tüpfelprobe, bei der

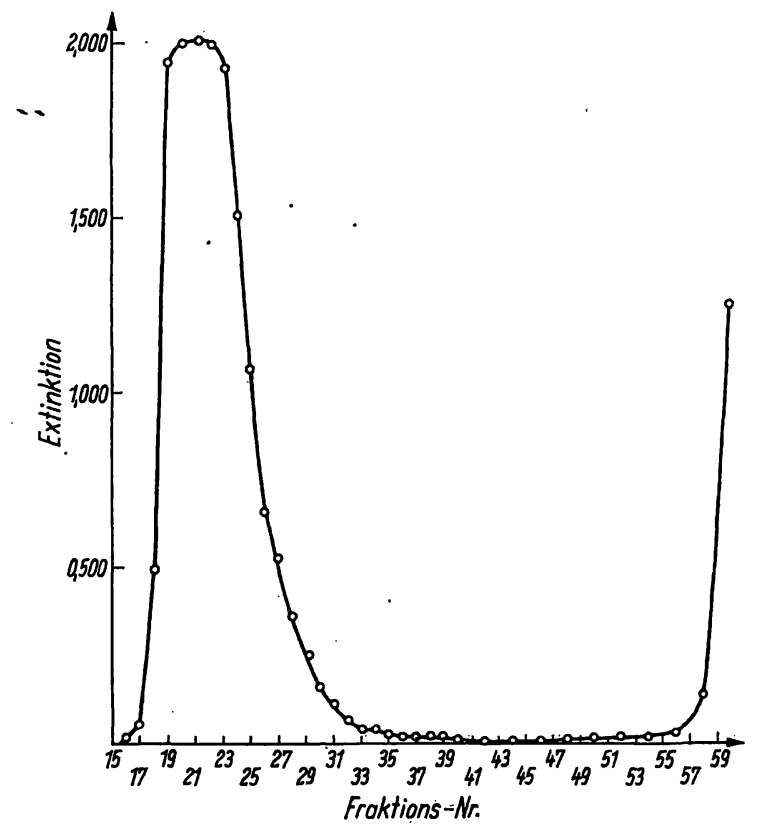

Abb. 1

Säulenchromatographische Trennung der Cholesterinester von den neutralen Lipioden. Lipoidbestimmung mit Hilfe der SPVReaktion. $\varepsilon=0,100$ entspricht $\sim 50 \mu$ g Fraktion.

Die völlige Lipoidfreiheit der Fraktionen 40-47 schließt eine Kontamination der Cholestinester durch andere Lipoide aus 
aus jeder Fraktion jeweils ein Tropfen auf einer Dünnschichtplatte mit Antimontrichlorid gefärbt wurde, brachte das gleiche Ergebnis. Eine Dünnschichtchromatographie der vereinten Gipfel (Glas 17-34 und 53-69) ergab, daß der erste Gipfel ausschließlich Cholesterinester, und zwar in den Proportionen des Ausgangsgemisches enthielt (Abb.2a), der zweite Gipfel die übrigen neutralen Lipoidfraktionen, nämlich Triglyceride und freies Cholesterin.

Nach unserer Erfahrung mit der chromatographischen Trennung der neutralen Lipoide nach LIPSKY und Mitarbeitern (21) ist die von uns. gewählte chromatographische Trennung an Florisil nach CARrol (20) der Methode von LIPSKY an Kieselsäure vorzuziehen. Trotz geringeren Säulendurchmessers ist dic Fließgeschwindigkeit durch die Florisil-Säule wesentlich größer und damit die benötigte Zeit kürzer. Außerdem sind die zur Elution aufeinanderfolgender Fraktionen notwendigen Erhöhungen der Konzentration von Äther in Petroläther in der Florisil-Säule wesentlich größer als in der Kieselsäure-Säule; so werden Triglyceride in der

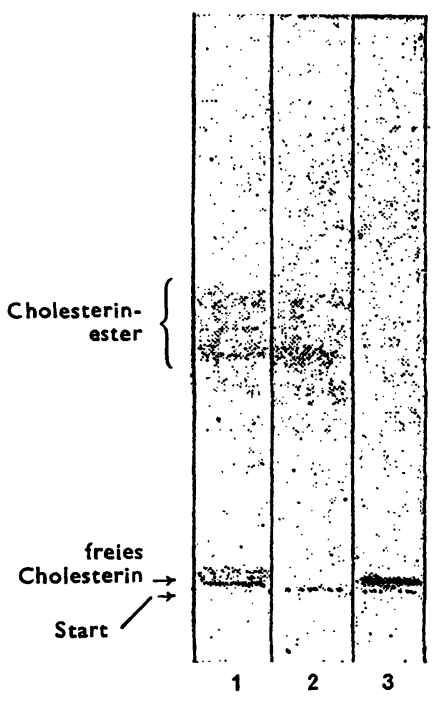

a)

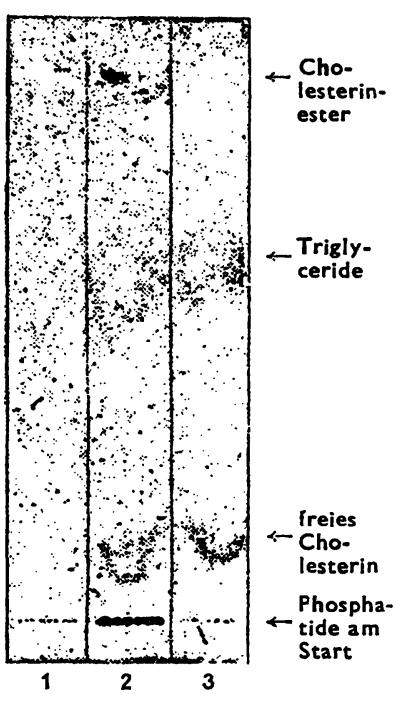

b)
Abb. 2

Dünnschichtchromatographische Trennung der Cholesterinester von den übrigen Lipoiden

a. Cbromatogramm der Cbolesterinester nacb (18):

1: Gesamtlipoidextrakt

1: Gesamtlipjidextrakt

2: Cholesterinester nach Sâulenchroma-
tographie
3weite neutrale Lipjidfraktion nach Säulenchromatographie (Gemisch aus Triglyceriden und freiem Cholesterin).
In Bahn 1 und 2 ist die kleine 5. Fraktion (PF) photographisch schwer darstellbar.

b. Cbromabogramm der Gesamtlipoide (19): (Fließmittel Petroläther: Xthylmethylketon: Eisessig 95:4:1; Nachweis mit konzentrierter Schwefelsäure und Veraschen)

1: Cholesterinester nach Säulenchroma- 3: Zweite neutrale Lipoidfraktion nach

2: Gesamtlipoidextrakt

Säulenchromatogtaphie.

Florisil-Säule durch eine Erhöhung der Konzentration von $5 \%$ Äther auf $15 \%$ Äther eluiert, während in der Kieselsäure-Säule die Triglyceride bereits durch eine Konzentrationserhöhung von $10 / 0$ auf $3 \%$ Äther eluiert werden. Die Cholesterinesterfraktion wurde zur Trokkene eingeengt und nach Zugabe von $40 \mathrm{ml} \mathrm{5 \%}$ methanolischer Salzsäure 9 Stunden bei $80^{\circ}$ zur Methylveresterung am Rückflußkühler gekocht. Anschließend wurde nach Zugabe einer geringen Menge Wasser
$6 \mathrm{mal}$ mit Petroläther:Äther $1: 1$ ausgeäthert, die vereinigten Ätherextrakte wurden mit halbgesättigter $\mathrm{Bi}$ carbonatlösung, anschließend mit Wasser, säurefrei gewaschen. Über Natriumsulfat wurde über Nacht getrocknet. Eine dünnschichtchromatographische Kontrolle zeigte keine Cholesterinester mehr.

Die Isolierung der Methylester der Fettsäuren aus den Cholesterinestern erfolgte wiederum an der FlorisilSäule. Der Vorlauf mit $60 \mathrm{ml}$ Petroläther enthielt bereits eine mit Antimontrichlorid anfärbbare Fraktion, die aber sicher nicht mit den natürlichen Cholesterinestern identisch ist, sondern ein Reaktionsprodukt mit der methanolischen Salzsäure, möglicherweise Cholesterylchlorid, darstellt. Dieses Reaktionsprodukt, dessen Abtrennung vor Einsatz der Methylester in die Gaschromatographie ratsam ist, läuft bei der Dünnschichtchromatographie der Cholesterinester (18) bis zur Lösungsmittelfront und kann dadurch leicht identifiziert werden. Die Methylester wurden mit 5\% Äther in Petroläther eluiert; am einfachsten wird ihr Erscheinen durch Tüpfeln auf Dünnschichtplatten und Nachweis nach Besprühen mit konzentrierter oder $50 \%$ iger Schwefelsäure und anschließendem Erhitzen auf $160^{\circ}$ festgestellt. Die Methylester wurden zur Trockene gebracht und in kleinsten Mengen Aceton oder Methanol aufgenommen. Die anschließende Gaschromatographie erfolgte an Bernsteinsäure-Butandiol-Polyester- und Bernsteinsäure-Äthylenglykol-Polyester-Säulen, präpariert nach den Angaben von CraIg und Murty (22) am Fraktometer $116 \mathrm{E}$ (Perkin-Elmer) bei $198^{\circ}$ mit Helium als Trägergas, Strömungsgeschwindigkeit $120 \mathrm{ml} / \mathrm{min}$. Der Nachweis der Fraktionen erfolgte mit einem Flammenionisationsdetektor. Ein Teil der Methylester wurde in methanolischer Lösung über Palladiumkohle hydriert; anschließend wurde filtriert, eingeengt und in die Gaschromatographie eingesetzt.

\section{Ergebnisse}

Typische Befunde für die idiopathische Hypercholesterinämie finden sich in Tabelle 1. Hier ist das Verhalten der Plasmalipoide eines Patienten (Fall So.) im Verlaufe von 10 Monaten dargestellt. Man erkennt die Erhöhung des Gesamtcholesterins, der Phosphatide, den normalen Esterquotienten, eine leichte Erhöhung der Neutralfette, die sich auch in der Serumtrübung ausdrückt; man erkennt ferner das weitgehend parallele Verhalten von Cholesterin und Phosphatiden. Der Verlauf in den ersten vier Monaten zeigt die Auswirkungen einer sehr fettarmen, auf Pflanzenöle umgestellten Kost, durch die der Cholesterinspiegel vorübergehend in den Normalbereich gesenkt werden konnte. Die späteren Werte sind z. T. durch ungenügende Einhaltung des Kostplanes zu erklären; spontane Schwankungen sind aber nicht auszuschließen.

Tabelle 2 gibt die quantitative Auswertung von Dünnschichtchromatogrammen der Cholesterinester wieder. Bei allen Patienten, die (mit Ausnahme von Po. und Wa.) typische hypercholesterinämische Xanthome aufwiesen, lag die Verteilung der Cholesterinester im 
Tab. 1

Chemische Verlaufsbeschreibung des Falles So. (idiopathische Hypercholesterinämie)

(Diät, keine medikamentöse Therapie)

\section{Datum}

Trübung

Gesamtcholesterin mg\%

Freies Cholesterin $\mathrm{mg} \%$

Ester-Cholesterin $\mathrm{mg} \%$

Esterquotient \%

Phosphatide mg\%

Veresterte Fettsäuren mg\%

Gesamtlipoide $\mathrm{mg} \%$

Neutralfett errechnet, $\mathrm{mg} \%$

$\begin{array}{rrrrrr}17.8 . & 23.8 . & 30.8 . & 6.9 . & 13.9 . & 28.9 . \\ 1,160 & - & 0,292 & 0,355 & 0,375 & 0,410 \\ 764 & 793 & 520 & 476 & 504 & 582 \\ 258 & 256 & 160 & 192 & 186 & 208 \\ 506 & 537 & 360 & 284 & 318 & 374 \\ 66 & 68 & 69 & 60 & 59 & 64 \\ 462 & 485 & 380 & 445 & - & - \\ 1002 & 1020 & 918 & 1110 & - & - \\ - & - & - & - & - & - \\ 407 & 371 & 476 & 698 & - & -\end{array}$

1) Nach Diätfehler während der Weihnachtstage.

Tab. 2

Cholesterinester im Serum bei idiopathischer Hypercholeștẹ̦inämie

(in Prozenten der gesamten Ester)

\begin{tabular}{|c|c|c|c|c|c|c|c|c|}
\hline Fall & $\left.\mathrm{GF}^{1}\right)$ & $\left.\mathrm{MF}^{1}\right)$ & $\left.\mathrm{DF}^{1}\right)$ & $\left.\mathrm{TF}^{1}\right)$ & $\left.\mathrm{PF}^{1}\right)$ & $\begin{array}{c}\text { Gesamt- } \\
\text { cholesterin } \\
\mathrm{mg} \%\end{array}$ & $\begin{array}{c}\text { Freies } \\
\text { Cholesterin } \\
\text { mg\% }\end{array}$ & $\begin{array}{l}\text { Ester- } \\
\text { quotient }\end{array}$ \\
\hline So., 48 Jahre $\widetilde{\delta}$ & 15,8 & 24,3 & 46,6 & 12,6 & 1,2 & 764 & 258 & 66 \\
\hline Po., 64 Jahre ô & 13,6 & 22,7 & 43,5 & $\left.18,6^{2}\right)$ & 1,6 & 364 & 103 & 69 \\
\hline Wa., 47 Jahre $q$ & 17,5 & 23,2 & 44,6 & 12,7 & 2,7 & 428 & 131 & 69 \\
\hline Br., 56 Jahre $q$ & 16,4 & 24,3 & 45,5 & 12,7 & 1,1 & 455 & 128 & 72 \\
\hline Rö., 53 Jahre $q$ & 17,2 & 23,8 & 37,3 & $\left.18,3^{2}\right)$ & 3,4 & 452 & 133 & 70 \\
\hline Lu., 21 Jahre & 17,2 & 22,6 & 41,7 & 16,6 & 1,8 & 652 & 206 & 68 \\
\hline $\begin{array}{l}\text { Mittelwerte der Normalwerte } \\
\text { beim Erwachsenen }(n=14)\end{array}$ & 16,1 & 23,6 & 46,7 & 11,8 & 2,0 & & & \\
\hline Mittlere Abweichung vom & & & & & & & & \\
\hline Mittelwert & $\pm 0,5$ & $\pm 0,5$ & $\pm 0,7$ & $\pm 0,5$ & $\pm 0,1$ & & & \\
\hline Streuung der Normalwerte & 2,0 & 1,7 & 2,4 & 1,7 & 0,5 & & & \\
\hline
\end{tabular}

1) GF: Ester der gesättigten Fettsäuren, MF: der einfach ungesättigten Fettsäuren, DF: der Dienfettsäuren, TF: der Tri- und Tetraenfẹttsäuren, PF: der hochungesättigten Fettsäuren.

2) Die Patienten deckten ibren Fettbedarf zum großen Teil aus pflanzlichen Keimölen.

Tab. 3 -

Cholesterinester des Falles So. (in Prozenten der gesamten Ester) bei gaschromatographischer und dünnschichtchromatographischer Untersuchung des gleichen Serums; Gesamtcholesterin 455 mg\%, Cholesterinester 314 mg\%.

\begin{tabular}{|c|c|c|c|c|c|c|c|}
\hline \multicolumn{4}{|c|}{ Gaschromatographie } & \multicolumn{4}{|c|}{ Dünnschichtchromatographie } \\
\hline & $\begin{array}{l}\text { BGP-Säule }{ }^{1} \text { ) } \\
\% \\
\text { nach Um- } \\
\text { rechnung aus } \\
\text { Hydrierung } \\
\text { (a) }\end{array}$ & $\begin{array}{c}\text { BBP-Säule }{ }^{2} \text { ) } \\
\% \\
\text { direkt } \\
\text { berechnet } \\
\text { (b) }\end{array}$ & $\begin{array}{c}\text { BGP-Säule } \\
\% \\
\text { direkt } \\
\text { berechnet } \\
\text { (c) }\end{array}$ & $\begin{array}{c}\text { Vergleichswerte } \\
\text { aus } \\
\text { BGP-Säule } \\
\% \\
\left(\frac{a+c}{2}\right)\end{array}$ & $\begin{array}{c}\% \\
\text { Versuch A }\end{array}$ & $\begin{array}{c}\% \\
\text { Versuch B }\end{array}$ & \\
\hline $\begin{array}{l}C_{14: 0} \\
C_{15: 0} \\
C_{16: 0}\end{array}$ & $\begin{array}{r}1,1 \\
0,3 \\
13,8\end{array}$ & $\begin{array}{r}1,0 \\
0,3 \\
14,7\end{array}$ & $\begin{array}{r}0,9 \\
0,2 \\
14,1\end{array}$ & 14,5 & 12,8 & 13,0 & $C_{16: 0}$ und $C_{18: 0}$ \\
\hline $\begin{array}{l}C_{16: 1} \\
C_{17: 0} \\
C_{18: 0} \\
C_{18: 1}\end{array}$ & $\begin{array}{r}7,8 \\
0,7 \\
1,1 \\
24,3\end{array}$ & $\begin{array}{c}9,0 \\
1,0 \\
+ \\
24,8\end{array}$ & $\begin{array}{c}8,0 \\
0,4 \\
1,1 \\
24,3\end{array}$ & 32,2 & 28,1 & 27,4 & $C_{16: 1}$ und $C_{18: 1}$ \\
\hline $\begin{array}{l}\bar{C}_{18: 2} \\
C_{18: 3}\end{array}$ & $\begin{array}{c}45,3 \\
+\end{array}$ & $\begin{array}{r}42,0 \\
1,6\end{array}$ & $\begin{array}{c}45,3 \\
+\end{array}$ & 45,3 & 45,4 & 45,3 & $\mathrm{C}_{18: 2}$ \\
\hline $\mathrm{C}_{20: 4}$ & 5,6 & $5,1 ?$ & 5,6 & 5,6 & 12,0 & 12,4 & $\mathrm{C}_{20: 4}$ \\
\hline Polyen & & $0,7+$ & & unbekannt & 1,8 & 1,9 & Polyen \\
\hline
\end{tabular}

1) $\mathrm{BGP}=$ Bernsteinsäure-Äthylenglykol-Polyester

2) $\mathrm{BBP}=$ Bernsteinsäure-Butandiol-Polyester 
Normalbereich. Eine Ausnahme bildete eine Vermehrung der TF-Fraktion in den Fällen Po. und Rö., die bei Po. auf Kosten aller Fraktionen, bei Rö. in erster Linie auf Kosten der DF-Fraktion ging. Die Vermehrung der Tri- und Tetraensäuren enthaltenden TF-Fraktion erklären wir durch die von den Patienten eingenommene pflanzenölreiche Kost, da sowohl Ahrens u. Mitarb. (23) als neuerdings auch CRAMÉr und BJöRNTORP (24) gezeigt haben, daß vermehrte Zufuhr hochungesättigter Fettsäuren zur Anhäufung entsprechender Cholesterinester im Serum führt. Wir konnten kürzlich bestätigen, daß Verabreichung von Arachidonsäureäthylester zu
Sonderstellung ein, weil die Lipoidvermehrungen im Plasma nicht auf eine bestimmte Substanz und ihr biochemisch oder strukturell sehr nahestehende Substanzen beschränkt sind, sondern die Vermehrung mehrerer, häufig sogar vieler Lipoide festzustellen ist. Um zu zeigen, welche Lipoide im einzelnen an den Vermehrungen beteiligt sind, sollten viele Fälle fraktioniert analysiert werden. Wendet man dieses Prinzip auf die idiopathische familiäre Hypercholesterinämie an, so zeigt sich in jedem Fall nicht nur eine Vermehrung des Gesamtcholesterins sondern auch eine Vermehrung der Phosphatide, daneben, bei fettreicher Ernährung, eine

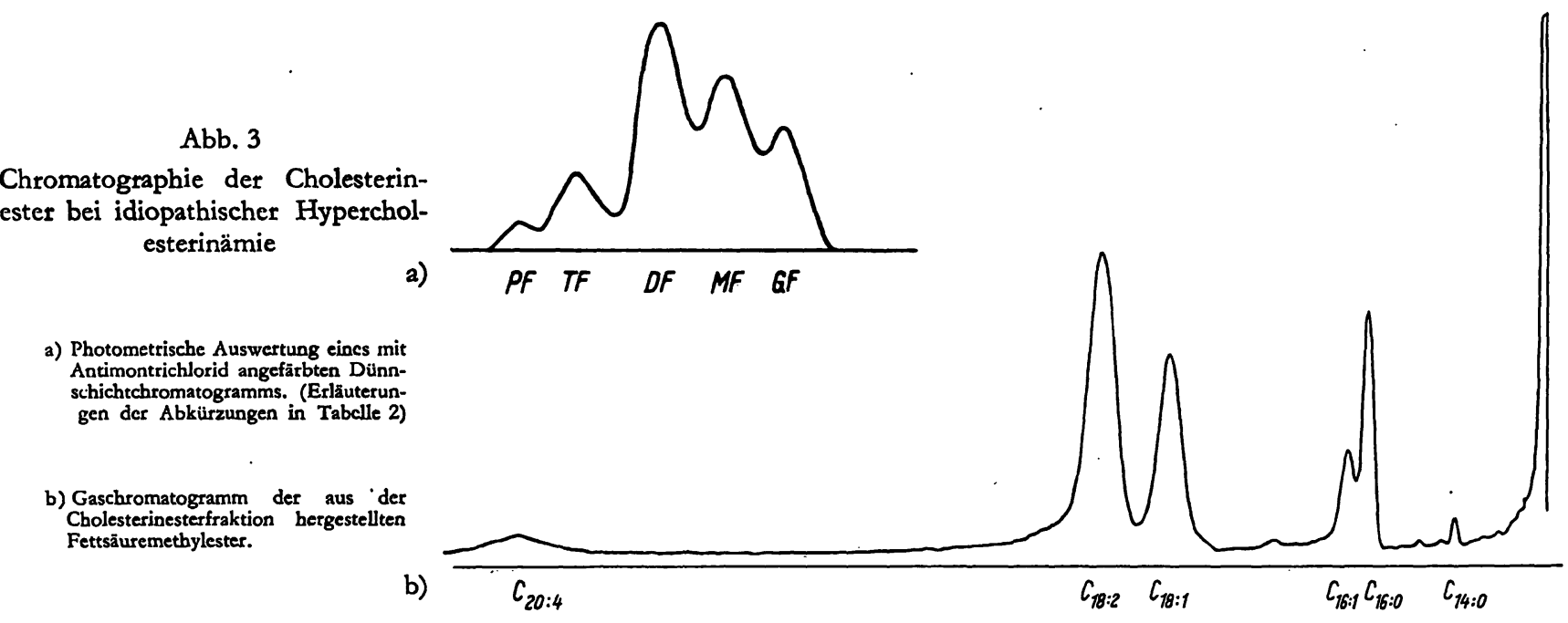

einer Vermehrung der Arachidonsäureester des Cholesterins im Plasma führt. Unsere Befunde einer normalen Esterverteilung bei idiopathischer Hypercholesterinämie stehen in Widerspruch zu Angaben von Schrade und Mitarb. (25), die auf Grund gaschromatographischer Analysen bei „,idiopathischer Hyperlipidämie“ eine deutliche relative Verminderung der Linolsäureester und der Ester der hochungesättigten Fettsäuren, dagegen eine relative Vermehrung der Ester von Palmitin-, Palmitolein- und Ölsäure festgestellt haben. Um diesen Widerspruch aufzuklären, haben wir in einem zuverlässig frischen Serum eines diagnostisch eindeutigen Falles von idiopathischer, xanthomatöser Hypercholesterinämie nach längerem Absetzen jeglicher Therapie (Fall So.) die Fettsäuren der Cholesterinester gaschromatographisch getrennt und bestimmt. Abbildung 3 gibt Dünnschicht- und Gaschromatogramme nebeneinander wieder. In Tabelle 3 sind die quantitativen Auswertungen einander gegenübergestellt. Die Befunde zeigen, daß die Auswertung der Dünnschichtchromatogramme in allen entscheidenden Punkten mit den Ergebnissen der Gaschromatographie übereinstimmt und bestätigen dạmit die Richtigkeit der dünnschichtchromatographischen Analyse. (Die Gegenüberstellung der Auswertungen verschiedener Gaschromatographien zeigt außerdem die auch dieser Methode innewohnende Fehlerbreite).

\section{Diskussion}

Unter den angeborenen Stoffwechseldefekten nehmen die Störungen des Stoffwechsels der Plasmalipoide eine
Vermehrung der Neutralfette und bei reichlicher Zufuhr von Carotinen auch eine Hypercarotinämie.

Das Verhalten der Carotine als ausschließlich exogener Lipoide beweist, daß beim Anstieg der Lipoidspiegel Löslichkeitsphänomene im Spiele sind, wenn man nicht die abwegige Annahme machen will, daß ein allen Lipioden gemeinsames abbauendes Enzym fehlt. Löslichkeitsphänomene, die in der Struktur der Lipoproteine eine Rolle spielen (26), sind vermutlich auch dafür verantwortlich, daB Cholesterin und Phosphatide, von seltenen Ausnahmen abgesehen, sich im Plasma gleichsinnig verhalten, und daß es selbst unter experimentellen Bedingungen nicht gelingt, eine isolierte Vermehrung oder Verminderung einer der beiden Substanzgruppen . hervorzurufen. So führt Cholesterinfütterung des Kaninchens zu einem Anstieg der Phosphatide (27); durch Infusion von Phosphatiden kann man einen Anstieg des Cholesterins erreichen (28). Dementsprechend ist auch zu erwarten, daß die isolierte Störung des Stoffwechsels eines Plasmalipoides zu einer Anhäufung der anderen führt, so daß sich die Notwendigkeit ergibt, den Stoffwechsel aller Plasmalipoide entsprechend zu untersuchen.

Unsere Befunde zeigen, daß bei der idiopathischen Hypercholesterinämie die relative Zusammensetzung der Cholesterinester normal ist, daß also alle Cholesterinester an der Zunahme des Gesamtcholesterins in gleicher Weise beteiligt sind. Damit wird die isolierte Störung des Stoffwechsels eines Cholesterinesters als Ursache der Hypercholesterinämie unwahrscheinlich. $\mathrm{Da}$ auch der 
Cholesterinesterquotient bei dieser Krankheit normal ist, kommt auch eine Störung der gesamten Esterbildung bzw. Esterspaltung als der der Hypercholesterinämie eigentümliche biochemische Grundeffekt nicht in Frage. Auch auf Grund von Messungen des Plasmacholesterinumsatzes (29) ist es wenig wahrscheinlich, daß der primäre Defekt Stoffwechselreaktionen betrifft, die an Synthese oder Abbau der Plasmacholesterine beteiligt sind.

Für eine Erörterung weiterer, hier nicht geprüfter pathogenetischer Möglichkeiten darf auf kürzlich an anderer Stelle mitgeteilte Zusammenfassungen $(30,31)$ verweisen werden.

Abschließend scheint eine Bemerkung über die chemische Diagnose der idiopathischen Hypercholesterinämie angebracht. Die Literatur der neueren Zeit gibt häufig an, daß die Neutralfettvermehrung Ausmaße erreichen kann, durch die das Serum leicht trüb, gelegentlich sogar stark getrübt erscheint. Manchmal sind solche
Fälle als idiopathische Hyperlipämie diagnostiziert worden. Im allgemeinen erreicht aber die Neutralfettvermehrung bei der idiopathischen Hypercholesterinämie nicht das gleiche Ausmaß wie bei der idiopathischen Hyperlipämie; in Zweifelsfällen muß die Relation zu dem jeweiligen Cholesterinspiegel berücksichtigt werden $(2,31)$. Wird durçh eine fettarme Diät der Neutralfettspiegel gesenkt, dann bleiben bei der idiopathischen Hypercholesterinämie fast immer deutlich erhöhte Cholesterinspiegel bestehen, während bei der idiopathischen Hyperlipämie die Cholesterinspiegel eher als die Neutralfettspiegel den Normbereich erreichen. Wird auch das klinische Bild zur Diagnose herangezogen, so besteht ohnehin meist kein Zweifel an der nosologischen Zuordnung. Lediglich Fälle, die zufällig durch die Aufdeckung chemischer Veränderungen gefunden werden, bieten die geschilderten diagnostischen Schwierigkeiten, die zeigen, daß manchmal nur der chemische Längsschnitt eine sichere Abgrenzung exlaubt.

\section{Literatur}

1. Thannhauser, S. J. und H. Magendantz, Ann. intern. Med. 11, 1662 (1938). - 2. Thannhauser, S. J., Lipidoses. 3. Auflage. Grune \& Stratton, New York-London; (1958). - 3. FREDRICKson, D. S., Essential familiar hyperlipidemia. In: The metabolic basis of inherited disease. McGraw Hill, New York-TorontoLondon, (1960). - 4. Zöllner, N., Stoffwechsel der Steroide und Carotinoide. In: Thannhausers Lehrbuch des Stoffwechsels und der Stoffwechselkrankheiten; Thieme, Stuttgart (1957). 5. Schettler, G., Lipidosen. In: Handbuch der Inneren Medizin, Bd. VII, 2. Teil. Berlin-Göttingen-Heidelberg, Springer (1955). 6. Zöllner, N., Verh. Dtsch. Ges. inn. Med. 64, 153 (1958). 7. SPERrY, W. M., Lipide Analysis. In: Methods of Biochemical Analysis, Bd. II, Interscience Pub. New York-London, (1955). 8. Zak, B., R. C. Dickenman, E. G. White, H. Burnetr und P. J. Chernex, Amer. J. Clin. Path. 24, 1307 (1954). - 9. Zlatkis, A., B. ZAK und A. J. Boyle, J. Laborat. Clin. Med., S. Louis 41, 486 (1953). - 10. Bartlett, G. R., J. Biol. Chemistry 234, 466 (1959). - 11. Rapport, M. M. und N. Alonzo, J. Biol. Chemistry 217, 193 (1955). - 12. Chabrol, E. und R. Charonnat, Presise méd., Paris 45, 1713 (1937). - 13. Chabrol, E., M. BöszörmenYr und P. Fallot, Sem. Hôp. Paris 25, 3446 (1949). - Zöllner, N. und K. KIRSCH, Zschr. ges. exper. Med. 135, 545 (1962). 15. ZöLLNER, N., Lipoidstoffwechsel. In: Thannhausers Lehrbuch des Stoffwechsels und der Stoffwechselkrankheiten. Thieme,
Stuttgart, 1957. - 16. EgGstein, M., Medizin und Ernährung 2, 1 (1961). - 17. ZöLLNER, N., K. KIrsch und G. AMIN, Verh. Dtsch. Ges. inn. Med. 66, 677 (1960). - 18. ZölLNER, N., G. Wolfram und G. Amrn, Klin. Wschr. 40, 273 (1962). - 19. ZöLLNER, N. und G. Wolfram, Klin. Wschr.40, 1098 u.1101 (1962). -20. Carroll, K.K., J.Lipid Research 2, 135 (1961). - 21. LIPSKY, S. R., A. HaAvik, C. L. Hopper und R. W. McDivitt, J. Clin. Invest. 36, 234 (1957). - 22. CRAIG, B. M. und N. L. Murty, J. Amer. Oil. Chem. Soc. 36, 549 (1959). - 23. Ahrens, E. H., jr., W. Insuld, jr., J. Hirsch, W. Stoffer, M. K. Peterson, J. E. Farquhar, T. Mirler und H: S. Thomasson, Lancet I, 115 (1959). - 24. Cramér, K. und P. Björntorp, Acta med. Scand. 171, 441 (1962). - 25. Schrade, W., R. Biegler und E. Böhle, J. Atheroscler. Res. 1, 47 (1961). - 26. ZöLLNER, N., Dtsch. med. Wschr. 83, 448 (1958). - 27. ZöLLnER, N., Pathologie-Biologie 7, 163 (1959). - 28. Byers, S. C. und N. Friedman, Amer. J. Physiol. 193, 435 (1958). - 29. Hellman, L., R. S. Rosenfeld, M. L. Edinoff, D. K. Fukushima, T. F. Galilagher, C. I. Wang und D. Adlersberg, J. Clin, Invest. 34, 48 (1955). - 30. Zöllner, N., Mschr. Kinderheilk. 110, 148 (1962). - 31. ZölLNER, N., Störungen des Fettstoffwechsels. Glycerinlipoidosen und Cholesterinosen. In: Erbliche Stoffwechselstörungen, Urban \& Schwarzenberg, München, (1962).

Prof. Dr. med. Nepomuk ZölLner

Medizinische Poliklinik der Universität München 8 München 15, Pettenkoferstr. 8 a 